\title{
Sleep Habits and Occurrence of Lowback Pain among Craftsmen
}

\author{
Gabriel O. AYENI ${ }^{1}$, Oladire OLANIYI ${ }^{1}$, Oluwasegun A. AYENI ${ }^{2}$ \\ ${ }^{1}$ Dept of Physiotherapy, Federal Medical Centre, Owerri, Imo St, Nigeria \\ ${ }^{2}$ Dept of Mathematics (Statistics), Ekiti State University Ado Ekiti, Nigeria
}

\begin{tabular}{|c|c|}
\hline Article Info & ABSTRACT \\
\hline Article history: & \multirow{10}{*}{$\begin{array}{l}\text { Low back pain (LBP) is a leading cause of disability with high economic } \\
\text { and public health consequences. The study objective is to determine the } \\
\text { association between sleeping habits and occurrence of lowback pain } \\
\text { among craftsmen in Owerri. From April to May, } 2012 \text {, a cross-sectional } \\
\text { survey of randomly selected } 500 \text { craft workers was done. Data on socio- } \\
\text { demographic characteristics and selected lifestyle were collected using an } \\
\text { interviewer semi-structured questionnaire. Data analysis was done using } \\
\text { descriptive, inferential statistics of chi square and multiple regressions. } \\
\text { The findings of multiple regression analyses showed respondents who } \\
\text { sleep on soft/saggy surface were almost } 5 \text { times more likely to develop } \\
\text { LBP independently compared to those with relatively firm/hard surface } \\
\text { (OR = 4.56; CI = } 2.62-7.94 \text {; }=0.001) \text { Craftsmen with unsteady } \\
\text { sleeping posture were twice likely to develop LBP }(\mathrm{OR}=2.10 \text {, CI = } 1.04- \\
4.25, \text { p }<0.001) \text {. Longitudinal study is warranted to further explore the } \\
\text { relationship between sleep habits and lowback pain. }\end{array}$} \\
\hline Received March 25, 2014 & \\
\hline Revised Mau 2, 2014 & \\
\hline Accepted May 26, 2014 & \\
\hline Keyword: & \\
\hline Sleep surface & \\
\hline Sleep posture & \\
\hline Sleep duration & \\
\hline Craftsmen & \\
\hline Lowback pain & \\
\hline
\end{tabular}

Copyright (C 2014 Institute of Advanced Engineering and Science. All rights reserved.

\section{Corresponding Author:}

Gabriel O. AYENI,

Surgery / Orthopaedic Physiotherapy unit, Physiotherapy Dept,

Federal Medical Centre,

Owerri, PMB 1010, Imo State, Nigeria.

E-mail: ayenco_2@yahoo.com

\section{INTRODUCTION}

Low back pain (LBP) is a common, complex and difficult to manage health condition [1]. Approximately, $20 \%$ of the adult population experiences an episode of LBP at any given time and estimates of lifetime prevalence are around $80 \%$ [2]. Sanya et al [3] found point and 12-month prevalence among industrial workers in a south-west Nigeria city to be $59.7 \%$ and $59.5 \%$ respectively. The economic burden of LBP is significant. Most of the costs of LBP are associated with persistent or chronic LBP, i.e. LBP which lasts for more than 3 months [4]. There are several important consequences of LBP including work loss [5], disability and depression [6]. As a result of the increasing number of older people throughout the world and industrialization, the burden of LBP on the individual and society as a whole is expected to increase dramatically [7]. It is predicted that the greatest increases in LBP will be in developing nations [8]

Despite intensive research to enhance understanding, management is only moderately effective [9]. Evidence is beginning to accumulate that patients with LBP also report significant problems with their sleep [10],[11]. Poor sleep is known to cause a range of physiological and psychological effects [12]. From a clinical perspective, the presence of sleep problems has implications for the management of LBP. A recent study found that LBP patients who reported sleep disturbance were twice as likely to be hospitalized compared with those who did not [13]. Another research suggests that improved sleep quality might reduce the pain and 
daytime symptoms of patients with arthritis [14]. It is currently unclear how common sleep habits influence occurrence for patients who are seeking care for their LBP.

General LBP preventive programs frequently focus on the recognized biomechanical factors, workload and organizational issues [15] with minimal effort at identifying and controlling the risk disposing lifestyle. Presently, there is dearth of data on the association between sleep habits and occurrence of LBP among craftsmen in Nigeria. An enhanced knowledge of the relationship between sleeping habits effect on the occurrence of lowback pain in this high risk population would help in appropriate primary and secondary preventive approach. This study assessed the relationship between sleeping duration, posture, time, sleep surface and the occurrence of LBP amongst craftsmen.

\section{RESEARCH METHOD}

From April to May 2012 a descriptive cross-sectional survey was conducted among craftsmen in Owerri, South-east, Nigeria. Owerri is the capital of Imo State and is set in the heart of the Igbo land. A multi stage sampling design was used to select the study participants. The participants were craftsmen and were randomly selected across the three local government areas in Owerri. They include welders and panel beaters, carpenters and furniture men, mechanic, local soap and oil millers, tailors and weavers. After informed consent was obtained from each worker, interviews using structured questionnaire were conducted with participants with the help of trained field research assistants.

The Questionnaire was prepared in English and it has three sections. Section A focused on sociodemographic information such as age, marital status, educational level etc. Section B sought answer to question on LBP history such as present and past lowback history and section $\mathrm{C}$ focussed on selected sleep habits such as sleep duration etc of the respondents. Lowback pain case in this study was defined as pain or discomfort in the lowback area between twelfth rib and gluteal fold (lower $1 / 3$ of the back) with or without pain in one or both legs lasting one day or longer or strong enough to make the worker absent from work, in their life time. The control has no history of lowback pain that met the above definition.

The questionnaire was assessed for validity. Test-retest reliability was equally carried out to ensure the questionnaire reliability. Confidentiality of information was maintained throughout the study. This research was conducted in compliance with the Helsinki Declaration. Data was analyzed using SPSS computer software version 17 (SPSS, Inc., Chicago, IL). Both descriptive statistics of mean, standard deviation, frequency and Inferential statistics of chi square and multiple regressions were used for the data analysis with p-value set at 0.05 .

\section{RESULTS AND ANALYSIS}

Respondents' age was in the range of 19 to $58(35.2 \pm 8.98)$ years with more males $(84.1 \%)$ than females (15.9\%) having LBP. Married workers 213 (61.7\%) experienced more LBP compared to workers that were single. Mean duration of practice was $(8.3 \pm 4.35)$ years. Presented in Table 1 is the relationship between socio-demographic characteristics of the respondents and occurrence of LBP. Age, gender and years of work experience among other socio-demographic characteristics had significant relationship with incidence of LBP.

Table 1. Socio-demographic characteristics of respondents and occurrence low back pain

\begin{tabular}{|c|c|c|c|}
\hline Variable & Yes LBP & No LBP & P value \\
\hline \multicolumn{4}{|l|}{ Age (years) } \\
\hline$\leq 29$ & $92(26.7)$ & $57(36.8)$ & \multirow{4}{*}{$<0.001$} \\
\hline $30-39$ & $113(32.8)$ & $65(41.9)$ & \\
\hline $40-49$ & $118(34.2)$ & $33(21.3)$ & \\
\hline$\geq 50$ & $22(6.4)$ & 0 & \\
\hline \multicolumn{4}{|l|}{ Gender } \\
\hline Male & $290(84.1)$ & $118(76.1)$ & \multirow{2}{*}{0.025} \\
\hline Female & $55(15.9)$ & $37(23.9)$ & \\
\hline \multicolumn{4}{|l|}{ Marital status } \\
\hline Single & $132(38.3)$ & $70(45.2)$ & \multirow{2}{*}{0.168} \\
\hline Married & $213(61.7)$ & $85(54.8)$ & \\
\hline \multicolumn{4}{|l|}{ Education Level } \\
\hline Nil & $25(7.2)$ & $12(7.7)$ & \multirow{5}{*}{0.512} \\
\hline Primary & $47(13.6)$ & $22(14.2)$ & \\
\hline Secondary & $188(54.5)$ & $74(47.7)$ & \\
\hline Tertiary & $85(24.6)$ & $47(30.3)$ & \\
\hline Work Experience (years) & & & \\
\hline
\end{tabular}

IJPHS Vol. 3, No. 2, June 2014: 101-106 


\begin{tabular}{lccc}
$\leq 1$ & $87(25.2)$ & $45(29.0)$ & $<0.001$ \\
$2-4$ & $95(27.5)$ & $71(45.8)$ & \\
$\geq 5$ & $134(47.2)$ & $34(25.2)$ & \\
\hline
\end{tabular}

The relationship between craftsmen sleeping habits and occurrence of LBP is presented in Table 2 . Significantly related sleep habits with LBP occurrence were entered for multiple regression analyses. The findings of multiple regression analyses showed respondents who sleep on soft/saggy surface were almost 5 times more likely to develop LBP independently $(\mathrm{OR}=4.56 ; \mathrm{CI}=2.62-7.94 ; \mathrm{p}=0.001)$. Craftsmen/workers with unsteady sleeping posture, soft sleep surface were all significantly associated with the occurrence of LBP independently (Table 3)

Table 2. Respondents' sleep habits and occurrence of low back pain

\begin{tabular}{lccc}
\hline \multicolumn{1}{c}{ Variable } & Yes LBP & No LBP & P value \\
\hline Usual sleep duration (hours) & & & \\
$0-8$ & $282(81.7)$ & $122(78.7)$ & 0.462 \\
$>8$ & $63(18.3)$ & $33(21.3)$ & \\
& & & \\
Usual sleep surface & & $113(72.9)$ & $<0.001$ \\
Soft & $166(48.1)$ & $42(27.1)$ & \\
Hard & $179(51.9)$ & & \\
& & $13(8.4)$ & \\
Sleeping posture & & $36(23.2)$ & \\
Lie with the chest & $88(25.5)$ & $43(27.7)$ & \\
Lie on the sides & $79(22.9)$ & $63(40.6)$ & \\
Lie with the back & $68(19.7)$ & & \\
Unsteady & $110(31.9)$ & & \\
Sleep time (Pm) & & $39(25.2)$ & \\
$<9$ & $75(21.7)$ & 9.410 \\
$9-11$ & $235(68.1)$ & $95(10.8)$ & \\
$>11$ & $35(10.1)$ & & \\
\hline
\end{tabular}

Table 3. Prevalence and odds ratios for low back pain in relation to sleep habits

\begin{tabular}{llllll}
\hline Variable & Frequency (n) & Prevalence (\%) & p-value & adj. OR* & 95\% CI \\
\hline Usual sleep surface & & & & & \\
Hard & 221 & 44.2 & $<.001$ & 1.00 & $2.62-7.94$ \\
Soft & 279 & 55.8 & & 4.56 & \\
Sleeping posture & & & & & \\
Lie with the chest & 101 & 20.2 & $<.001$ & 1.00 & $0.13-0.64$ \\
Lie on the sides & 115 & 23.0 & & 0.29 & $0.22-0.83$ \\
Lie with the back & 111 & 22.2 & & 0.43 & $1.04-4.25$ \\
Unsteady & 173 & 34.6 & 2.10 & \\
\hline
\end{tabular}

*Adjusted odd ratio (Adj. OR) obtained from multiple logistic regression (adjusted for age and sex): $\mathrm{CI}=$ Confidence interval

\section{Relationship between sleep habits and occurrence of LBP}

This study demonstrated a significant association between usual sleep surface and the occurrence of LBP. Those who sleep often on soft surface were almost five times likely to develop LBP independently than sleeping on relatively hard/firm surface. Likewise, an association was found between usual sleep posture and the occurrence of LBP. Those who have unsteady sleep posture had increased risk of developing LBP by 2.1 times. Many factors could also be responsible for an individual to have unsteady sleep posture including LBP itself. Back care experts including Physiotherapists often recommend that patients (not all) or even healthy individuals endeavour to sleep face down or with sides as sleeping face up could predispose them to have or perpetuate their LBP. This study finding showed there was no significant relationship between the usual time of sleep and occurrence of lowback pain. It also showed no relationship between the duration of sleep and occurrence of lowback pain. $(\mathrm{p}>0.05)$

Tomita et al [16] in their study found no relationship between sleep duration and LBP. Nagasu et al [17] reported short sleep to be a risk factor for LBP. Nittera et al [18] in a prospective survey from Norway, involving only women and over a 17-year period, found that disrupted sleep was a risk factor for the onset of chronic pain and predictive for pain persistence (but not worsening of pain).

Certain sleep surfaces have resulted in complaints of low back discomfort, pain, or stiffness and shoulder pain [19] One study found that subjects developed back pain after sleeping on foam mattresses [20]. 
In a comparison of beds described as "hard," "softer," water, and water/foam, subjects with current back pain reported reduced pain after sleeping on "hard" beds [21]. Overall comfort while sleeping on the mattress is equally important as sufficient back support in helpful during sleep. Sleeping on a mattress that is too firm can cause aches and pains on pressure points. A medium-firm mattress may be more comfortable because it allows the shoulder and hips to sink in slightly [22]. Bergholdt et al [23] found that the waterbed and the foam mattress seemed superior to the hard mattress, especially when using the probably most relevant "worst case" data. There were no relevant difference between the effects of the water bed and the foam bed. They concluded that Waterbed and foam mattress' did influence back symptoms, function and sleep more positively as opposed to the hard mattress, but the differences were small. Bert et al [24] concluded that new bedding systems increased sleep quality and reduced back discomfort. The comfort and support of the sleep surface are related to problems of sleep quality and efficiency [25]. Jacobson et al, [26] in 2 separate studies, found that medium-firm mattresses reduced clinically diagnosed back pain, shoulder pain, spine stiffness, and positively affected sleep quality and that even subjects with minor sleep disturbances benefited significantly in sleep quality and efficiency with medium-firm bedding systems [27]. Hadler and Evans [28] concluded that medium-firm mattresses served to reduce low back pain more so than firm mattresses.

Presently, no formula exists for recommending bedding systems to meet specific sleep needs or for reducing sleep disturbances [29]. Health care professionals have little information to support recommending sleep surfaces. However, Jacobson et al [26] suggested that body weight may be one determining factor for choosing a bed. Despite the lack of guidelines, and cautions that physicians should avoid recommending firm mattresses, $75 \%$ of orthopedic surgeons' recommend firm or hard mattresses for the relief of back pain [30]. This present study has contributed to findings in LBP, however further research on patients with low back pain and sleep habits is required to delineate these complex relationships so that effective management can be achieved.

\section{CONCLUSION}

Sleep posture and surface showed significant relationship to the occurrence of lowback pain. Attention should be given to sleep habits in the prevention and management of lowback pain. Further longitudinal study focusing on sleep habits will be valuable.

\section{ACKNOWLEDGEMENTS}

The authors thank the various craftsmen groups who allowed their members to participate in the study. We thank Elizabeth A. Ayeni (Mrs.) for her assistance in proof reading this manuscript.

Funding: None

Competing interest: We declare we have no conflict of interest.

Ethical approval: Ethical approval was sought and obtained for this study. We comply with the principles laid down in the Declaration of Helsinki.

Originality: We certify that this work has not been published anywhere or submitted for publication in other journal.

\section{REFERENCES}

[1] Manchikanti L., Singh V., Datta S., Cohen S. P., Hirsch J. A., "Comprehensive review of epidemiology, scope, and impact of spinal pain”, Pain Physician, vol. 12, pp. E35-E70, 2009.

[2] Walker B. F., "The prevalence of low back pain: a systematic review of the literature from 1966 to 1998 ", J Spinal Disord, vol. 13, pp. 205-217, 2000.

[3] Sanya A. O., Omokhodion F. O., Ogwumike O. O., "Risk factors for low back pain among hospital workers in Ibadan, Oyo State, Nigeria", J. Nig. Soc. Physioth, vol/issue: 15(2), pp. 31-34, 2005.

[4] Walker B. F., Muller R., Grant W. D., "Low back pain in Australian adults: the economic burden", Asia Pac J Public Health, vol. 15, pp. 79-87, 2003.

[5] Marty M., Rozenberg S., Duplan B., Thomas P., Duquesnoy B., Allaert F., "Quality of sleep in patients with chronic low back pain: a case-control study”, Eur Spine J., vol. 17, pp. 839-844, 2008.

[6] Tucer B., Yalcin BM., Ozturk A., Mazicioglu MM., Yilmaz Y., Kaya M., "Risk factors for low back pain and its relation with pain related disability and depression in a Turkish sample", Turk Neurosurg, vol. 19, pp. 327-332, 2009.

[7] Stewart G. S., Wang B., Bignell CR., Taylor A. M., Elledge S. J., "MDC1 is a mediator of the mammalian DNA damage checkpoint”, Nature, 421, pp. 961-966, 2003.

[8] World Health Organization (WHO), "Scientific Group on the Burden of Musculoskeletal Conditions of the Start of the New Millennium. The burden of musculoskeletal conditions at the start of the new millennium", World Health Organ Technical Report Series, vol. 919, pp. 1-218, 2003. 
[9] Cohen S. P., Argoff C. E., Carragee E. J., "Management of low back pain”, BMJ, vol. 337, pp. a2718, 2008.

[10] Hush J. M., Refshauge K., Sullivan G., Souza L., Maher C. G., McAuley J. H., "Recovery: what does this mean to patients with low back pain?", Arthritis Rheum, vol. 61, pp. 124-131, 2009.

[11] Tang N. K. Y., Wright K. J., "Salkovskis PM. Prevalence and correlates of clinical insomnia co-occurring with chronic back pain", J Sleep Res, vol. 16, pp. 85-95, 2007.

[12] Dongen H. P., Maislin G., Mullington J. M., Dinges D. F., "The cumulative cost of additional wakefulness: doseresponse effects on neurobehavioral functions and sleep physiology from chronic sleep restriction and total sleep deprivation", Erratum appears in Sleep, vol/issue: 27(4), pp. 600, 2004.

[13] Kaila-Kangas L., Kivimäki M., Härmä M., Riihimäki H., Luukkonen R., Kirjonen J., Leino-Arjas P., "Sleep disturbances as predictors of hospitalization for back disorders - a 28-year follow-up of industrial employees", Spine, vol. 31, pp. 51-56, 2006.

[14] Davis G. C., Davis G. C., "Improved sleep may reduce arthritis pain”, Holist Nurs Pract, vol. 17, pp. 128-135, 2003.

[15] Vieira E., Kumar S., Narayan Y., "Smoking, no-exercise, overweight and low back disorder in welders and nurses", Int J. Ind. Ergs, vol/issue: 38(2), pp. 143-149, 2008.

[16] Tomita S., Arphorn S., Muto T., Koetkhalai K., Naing S., Chaikittiporn C., "Prevalence and risk factors of lowback pain among Thai and Myammar migrant seafood processing factory workers in SamortSarkon Province, Thailand", Ind. Health, vol. 48, pp. 283-291, 2010.

[17] Nagasu M., Sakai K., Ito A., Tomita S., Temmyo Y., Ueno M., Miyagi S., "Prevalence and risk factors for lowback pain among professional cooks working in school lunch services", BMC Public Health, vol. 7, pp. 171, 2007.

[18] Nittera A. K., Pripp A. H., Forsetha K. Ø., "Are sleep problems and non-specific health complaints risk factors for chronic pain? A prospective population-based study with 17 year follow-up", Scand J Pain, vol. 3, pp. 210-217, 2012.

[19] Akgun K., Birtane M., Akarirmak U., "Is local subacromial corticosteroid injection beneficial in subacromial impingement syndrome?”, J Clin Rheumat, vol. 23, pp. 496-500, 2004.

[20] Koul P. A., Bhat M. H., Lone A. A., Koul A. N., Wahid A., "The foam mattress-back syndrome", J Assoc Physicians India, vol. 48, pp. 901-902, 2000.

[21] Garfin S. R., Pye S. A., "Bed design and its effect on chronic low back pain - a limited controlled trial", Pain, vol. 10, pp. 87-91, 1981.

[22] Spine Health, "Choosing the Best Mattress for Lower Back Pain". 1999-2014 Spine-health.com.

[23] Bergholdt K., Fabricius R. N., Bendix T., "Better backs by better beds?” Spine, vol/issue: 33(7), pp. 703-8, 2008.

[24] Bert H. Jacobson, Ali Boolani, Doug B, Smith, "Changes in back pain, sleep quality, and perceived stress after introduction of new bedding systems", J Chiropr Med., vol/issue: 8(1), pp. 1-8, 2009.

[25] Addison R. G., Thorpy M. J., Roth T., "A survey of the United States public concerning the quality of sleep", $J$ Sleep Res, vol. 16, pp. 244, 1986.

[26] Jacobson B. H., Gemmell H. A., Hayes B. M., Altena T. S., "Effectiveness of a selected bedding system on quality of sleep, low back pain, shoulder pain, and spine stiffness", J Manipulative Physiol Ther., vol. 25, pp. 88-92, 2002.

[27] Jacobson B. H., Wallace T. J., Gemmell H., "Subjective rating of perceived back pain, stiffness and sleep quality following introduction of medium-firm bedding systems", J Chiropr Med., vol/issue: 5(4), pp. 128-134, 2006.

[28] Hadler N. M., Evans A. T., "Medium-firm mattresses reduced pain-related disability more than firm mattress in chronic, nonspecific low-back pain", ACP J Club, vol. 141, pp. 3, 2004.

[29] Enck P., Walten T., Walten T., Traue H. C., "Association between back pain, quality of sleep and quality of mattresses. Double-blind pilot study with hotels guests", Schmerz, vol. 11, pp. 205-207, 1999.

[30] Levy H., Hutton W. C., "Mattresses and sleep for patients with low back pain: a survey of orthopaedic surgeons", $J$ South Orthop Assoc, vol. 5, pp. 178-185, 2000.

\section{BIOGRAPHIES OF AUTHORS}

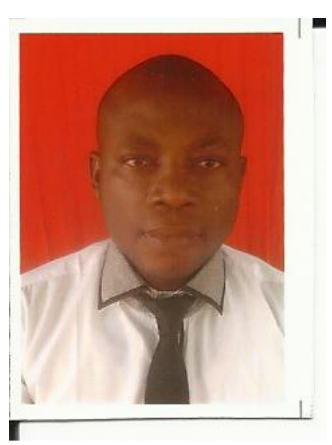

Gabriel O AYENI is an orthopaedic physiotherapist and a clinical researcher working with the federal hospital in Owerri Nigeria. He has Bachelor of Medical Rehabilitation (Physiotherapy) and Master of Public Health degree. His areas of special interest are Orthopaedic and trauma Physiotherapy, Exercise Therapy and Compliance, Epidemiology of chronic diseases and injuries, Health promotion, Electrotherapy. He has publications in these areas. 


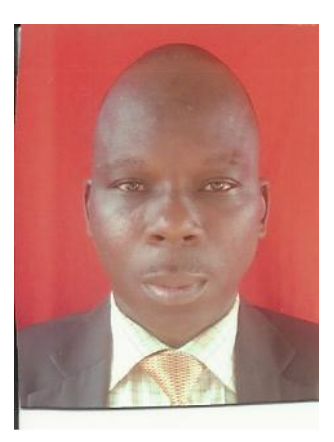

Oladire OLANIYI is a physiotherapist, administrator and clinical researcher working with the Federal hospital in Owerri Nigeria. He has Bachelor of Medical Rehabilitation (Physiotherapy) and Master of Science (Physiotherapy) degree. His areas of special interest are Neuro-Physiotherapy, Exercise Therapy and Compliance, Epidemiology of chronic diseases, Health promotion. He has publications in these areas.

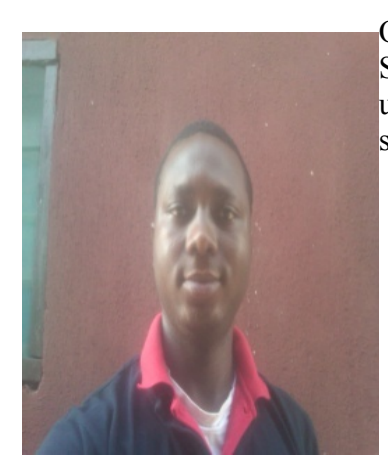

Oluwasegun A AYENI is Mathematician/Statistician. He has Diploma in Computer Science and a Bachelor of Science degree in Mathematics/Statistics. He is currently undergoing his Master degree programme. He has special interest in statistical analysis, software development and data management with some published works. 